\title{
Implementasi Master-slave Pada Embedded System Menggunakan Komunikasi RS-485
}

\author{
Agusma Wajiansyah ${ }^{1 *}$, Supriadi ${ }^{2)}$, Noval Ramadhan ${ }^{3)}$, Rizky Sandria ${ }^{4)}$, dan Lalu Muhammad Dian Pratama ${ }^{5)}$ \\ 1,2,3,4,5) Department of Information Technology, Politeknik Negeri Samarinda, Indonesia \\ Corresponding Email: *) agusma.wajiansyah@gmail.com
}

\begin{abstract}
The use of multiprocessor methods in robotics systems has a significant impact on overall robot performance. The Master-slave method is a model of a multiprocessor system where there are several processors that communicate with each other to carry out the robot's overall function. RS-485 can be used as a communication model in the master-slave method. RS-485 is a development of RS-232 which has the ability to communicate with several nodes. In this research, an experiment will be conducted to implement RS-485 to support the master-slave processor communication. Stages of research began with making system design, which includes the design of embedded hardware systems, the design of data communication protocols on RS-485 networks, software design, followed by implementation and testing. The test is carried out to measure the time response of the device to three data transmission models, namely broadcast, addressing slaves without responding and addressing slaves with responses. The test results carried out on three slaves with a communication speed of 9600 bps. Measured response time on broadcast data transmission is $8 \mathrm{~ms}$, and address slave without response is $7 \mathrm{~ms}$. Whereas delivery by addressing slaves with responses, shows that the measurement method cannot be applied.
\end{abstract}

Key words : RS-485, Master-Slave processor communication.

\section{Pendahuluan}

Sistem tertanam atau yang lebih dikenal dengan embedded system pada decade terakhir telah mendapat perhatian yang sangat signifikan. Ini dikarenakan sistem tertanam sangat flexible untuk diaplikasikan diberbagai bidang. Contoh pengaplikasiannya adalah sebagai perangkat pada bidang intrumentasi, pengendalian, komunikasi, entertainment, robotika dan lain sebagainya. Menurut [1] sistem tertanam adalah kombinasi perangkat keras dan perangkat lunak untuk merespon kejadian di sekitarnya dalam batas yang ditentukan. Sistem tertanam bisa terdiri dari komputer kecil dengan mikroprosesor atau mikrokontroler dan perangkat pendukungnya. Untuk menigkatkan kemampuan komputasi pada embedded system dapat digunakan beberapa microprocessor. Teknologi ini dikenal dengn istilah multiprocessor.

Penggunaan teknologi multiprocessor pada embedded system dapat memberikan dampak yang signifikan terhadap proses exekusi program. Contohnya pada aplikasi bidang robotika, pada penlitian [2] terukur peningkatan performance sebesar $7.3 \%$ jika dibandingkan dengan sistem berbasis single processor. Salah satu metode untuk digunakan pada sistem multiprocessor adalah metode Master-slave processor. Beberapa processor terhubung melalui kanal komunikasi, salah satu processor bertindak sebagai master dan sisanya sebagai slave. Komunikasi Master-slave processor dapat diterapkan dengan menggunakan media I2C, SPI atau komunikasi multidrop RS-485.

Menurut [3], Komunikasi multidrop RS-485 merupakan salah satu standar komunikasi serial yang dapat menjangkau jarak sepanjang $1.2 \mathrm{Km}$. untuk berkomunikasi, pada RS-485 menggunakan sepasang media penghantar berbentuk twisted. Standar ANSI TIA/EIA-485-A menetapkan kedua penghantar tersebut dengan notasi ' $A$ ' dan 'B'. pertukaran informasi pada RS485 direalisasikan dengan perubahan tegangan pada kedua penghantar tersebut. Jika tegangan pada penghantar 'A' lebih besar dari penghantar 'B' maka dikenal dengan logika high dan demikian pula sebaliknya.

Penerapan RS-485 telah dilakukan oleh [4]. Pada penelitian tersebut, ekperimental dilakukan dengan membangun 2 buah perangkat slave dan sebuah perangkat master yang terkoneksi dengan topologi jaringan BUS. Kedua perangkat slave bertujuan untuk melakukan penukuran temperature lingkungan dan kelembaban udara relative pada titik koordinat tertentu yang didapat dengan bantuan GPS receiver. Sedangkan perangkat master bertujuan untuk menampilkan informasi pengukuran. Dari hasil uji yang dilakukan 360 paket data terkirim selama 360 detik tanpa terjadi kesalahan.

Penerapan RS-485 juga telah dilakukan oleh [5]. Pada penelitian tersebut digunakan protocol MODBUS yang secara hirarki berjalan diatas RS-485. Komunikasi RS485 MODBUS digunakan untuk menghubungkan raspberry-pi dan inverter pada sistem pembangkit tenaga surya, dan selanjutnya sistem pembangkit ini terkoneksi kembali ke internet dengan menggunakan teknologi Internet of Think (IOT). Dengan terbentuknya komunikasi tersebut maka dapat dilakukan proses pengaturan dan monitoring sistem pembangkit tenaga surya tersebut. Penelitian yang berkaitan dengan pengapplikasian MODBUS pada jaringan komunikasi RS-485 juga dapat ditemukan pada [6][7]

Pada penelitian [8] menggunakan RS-485 untuk membangun smart classroom. Desain arsitektur melibatkan beberapa teknologi baru antara lain Internet Of Think (IoT). Komunikasi RS-485 digunakan untuk 
mengendalikan perangkat HAVAC pada classrooms dan juga untuk mengendalikan perangkat penerangan. Dengan adanya desain ini diharapkan akan memudahkan proses belajar mengajar dan administrasinya.

Pada penelitian [9] bertujuan untuk pemantauan bahan berbahaya pada angkutan transportasi. Penggunaan RS485 sebagai jaringan sensor yang digunakan untuk membaca kondisi sekitar bahan berbahaya yang diangkut pada kendaraan. Selain sensor, posisi kendaraan juga diakuisisi dengan menggunakan GPS (Global Positioning System). Semua parameter dari sensor dan posisi kendaraan kemudian dikirim ke pusat pemantauan melalui jaringan internet. pemantauan bahan berbahaya dilakukan secara real-time, sehingga dapat membuat sistem tranfortasi untuk bahan berbahaya menjadi lebih efektif dan transparan dan dapat mengurangi resiko terjadi kecelakaan.

Pada penelitian ini diterapkan protocol komunikasi untuk jaringan komunikasi multidrop RS-485 pada system master-slave multiprocesor. Berbeda dengan penelitian-penelitian yang telah dijelaskan, pada penelitian ini akan dibahas protocol komunikasi pada jaringan RS-485 yang digunakan. Ekperimental dilakukan dengan membangun 3 perangkat embedded system yang difungsikan sebagai prosessor slave. Ketiga perangkat embedded system tersebut ditanamkan program protocol komunikasi dan beberapa task sederhana pada program utamanya. Kemudian akan diukur respons time dari setiap processor slave terhadap tiga model pengiriman paket data yaitu secara broadcast, addressing slave dan addressing slave dengan response.

\section{Metodologi}

Pelaksanaan penelitian mengikuti langkah - langkah yaitu : desain sistem, implementasi dan pengujian. Desain sistem terdiri dari desain perangkat keras, desain protocol komunikasi untuk jaringan multidrop RS-485 dan desain perangkat lunak.

\section{A. Blok diagram sistem}

Desain sistem pada penelitian ini ditunjukan pada Gambar 1.

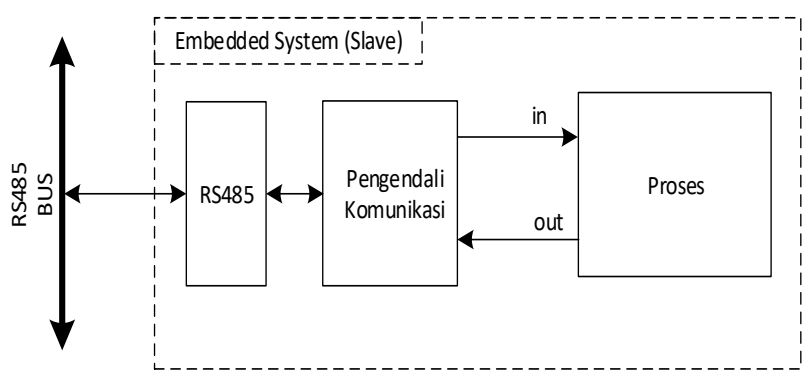

Gambar 1. Blok diagram modul slave

Setiap perangkat slave terhubung kedalam jaringan komunikasi membentuk topologi jaringan Bus. Pada jaringan ini hanya terdapat perangkat dengan 2 fungsi utama yaitu master dan slave. Pada penelitian ini hanya digunakan satu buah master dan 3 buah slave. Pada sistem master-slave multiprocessor, master merupakan processor aktif yang memulai untuk berkomunikasi sedangkan slave merupakan processor pasif yang hanya menerima komunikasi dari master.

Pada Gambar 1, blok Proses merupakan fungsi utama dari perangkat slave. Contoh dari Blok proses dapat berupa sistem kendali Motor DC, sistem Akuisisi data sensor dan lain-lain. Setiap proses memiliki parameter input dan output. kedua parameter inilah yang akan diatur atau dimonitor melalui bus RS-485 dengan perantara blok pengendali komunikasi.

Fungsi utama dari blok pengendali komunikasi adalah menyediakan protocol dalam proses pengiriman dan penerimaan data antara perangkat master dan slave, pada jaringan RS-485.

\section{B. Paket data}

Setiap data yang dikirim dari perangkat master ke slave atau sebaliknya, akan diencapsulasi hingga menjadi paket data. Paket data yang digunakan terdiri dari dua jenis yaitu paket data dari master ke slave (Request) dan paket data dari slave ke master (Response). Gambar 2 merupakan visualisasi dari kedua jenis paket data tersebut.

\begin{tabular}{|c|c|c|c|c|c|}
\hline SLV & nData & cmd & $\begin{array}{c}\text { Data } \\
1\end{array}$ & $\begin{array}{c}\text { Data } \\
2\end{array}$ & $\begin{array}{c}\text { Data } \\
n\end{array}$ \\
\hline
\end{tabular}

(a)

\begin{tabular}{|c|c|c|c|}
\hline nData & $\begin{array}{c}\text { Data } \\
1\end{array}$ & $\begin{array}{c}\text { Data } \\
2\end{array}$ & \\
\hline
\end{tabular}

(b)

Gambar 2. Paket Data (a) Request, (b) Response

Pada paket request, SLV ADDR merupakan data pertama yang dikirim. Berisi alamat slave yang dituju. SLV ADDR memiliki panjang data sebesar 1 byte, pemberian alamat dimulai dari $01 \mathrm{H}$ sampai dengan $\mathrm{FFH}$. Alamat $00 \mathrm{H}$ digunakan untuk keperluan broadcast. Data berikutnya adalah 'nData' yang memberikan informasi jumlah data terkirim.

Pada bagian 'cmd' dari paket data request, memberikan informasi perintah yang harus dilakukan oleh slave. Lebar data 'cmd' sebesar 1 byte, sehingga dapat dibentuk sebanyah 256 perintah. Bagian dari paket data berikutnya adalah 'Data 1', 'Data 2' sampai dengan 'Data n' merupakan parameter dari perintah. Setiap perintah dapat memiliki parameter atau tidak, tergantung dari keperluannya. Jumlah data yang dikirim maximal sebanyah 256 data, hal ini berlaku jika 'nData' berukuran 1 Byte.

Pada paket data Response hanya terdiri dari ' $\mathrm{nData}$ ' dan 'Data 1', 'Data 2' sampai dengan 'Data n' yang memiliki arti sama pada paket data request.

Data dikirim secara serial dengan menggunakan USART (Universal Synchronous and Asynchronous serial Receiver and Transmitter) yang telah tersedia pada mikrokontroller. Frame data pada USART ditunjukan pada Gambar 3. Setiap frame terdiri dari Star bit (St), 9 bit 
data (0 .. 8) dan Stop bit (Sp). Pada Bit data, bit ke-0 sampai dengan bit ke-7 merupakan data yang dapat berupa byte 'SLV ADDR', 'nData', 'cmd', 'Data 1', 'Data 2' sampai 'Data n'. sedangkan bit ke-8 pada bit data merupakan flag yang akan bernilai ' 1 ' jika yang dikirim adalah SLV ADDR dan sebaliknya.

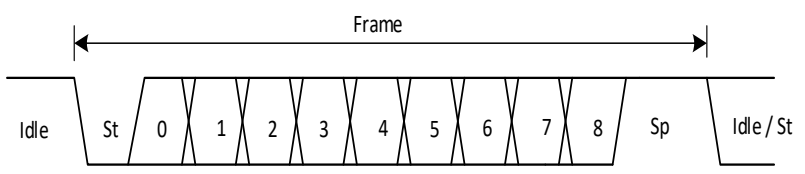

Gambar 3. Frame Data Serial

\section{Rancangan Perangkat Lunak}

Pengendali Komunikasi merupakan fungsi tambahan yang bertujuan untuk menyediakan protocol komunikasi. Saat proses penerimaan data, Pengendali Komuniksi melakukan pengecekan pada paket data yang datang. Jika alamat yang datang merupakan broadcast atau alamat yang sesuai maka akan dilakukan proses pembacaan data berikutnya. Proses ini ditunjukan pada Gambar 4. Penerimaan data bekerja secara interrupt dan juga menggunakan mode MPC (Multi processor Communication). Mode ini merupakan fitur komunikasi yang banyak dijumpai pada serial USART mikrokontroller. Pada mode MCP, beberapa processor dapat dikoneksikan pada jalur komunikasi yang sama. Setiap frame terdiri dari 9-bit data dan masing-masing 1 bit $S t$ dan $S p$. untuk tujuan pengalamatan menggunakan 1 bit terakhir yang mengindikasikan bahwa frame tersebut adalah frame alamat atau frame data, seperti yang ditunjukan pada Gambar 3.

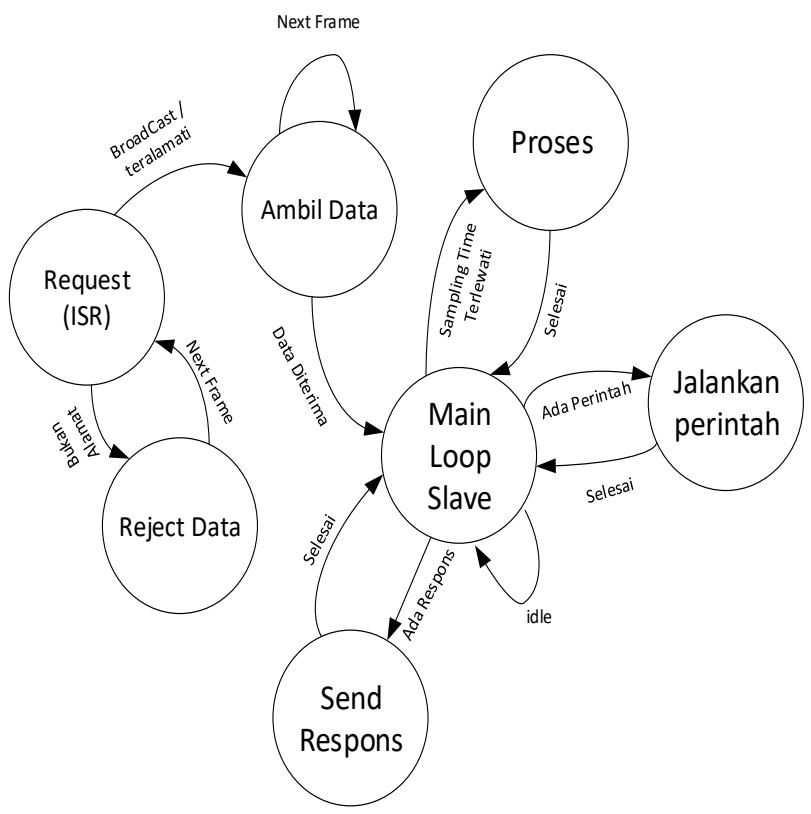

Gambar 4. State diagram perangkat lunak slave

Komunikasi dimulai oleh perangkat master. Data dari perangkat master hanya akan diterima oleh perangkat slave selama data dikirim secara broadcast atau dengan menyertakan alamat perangkat slave yang dituju. Proses pengiriman dan penerimaan data pada perangkat slave dilakukan secara interrupt dengan memfungsikan mode MPC. Jika frame data yang dikirim berupa data atau alamat dari perangkat slave yang lain, maka frame tersebut akan ditolak (Reject). Sedangkan jika frame tersebut berupa alamat dari perangkat slave dilanjutkan dengan data, maka frame tersebut akan diterima hingga proses pengiriman selesai. Setelah seluruh data diterima, perangkat slave tersebut akan memproses data yang masuk sesuai dengan protocolnya. Jika perangkat master mengiginkan respons, maka perangkat slave akan mengirimkan data kembali ke perangkat master. proses state pada perangkat slave ini ditujukan pada Gambar 4 .

\section{Response Time}

Response time merupakan ukuran waktu yang diperlukan suatu node untuk menanggapi permintaan dari node yang lain [10]. Pengukuran ini diperlukan untuk mengetahui performansi sistem komunikasi yang dibangun. Pada komunikasi master-slave Pengukuran Response time dapat dilakukan pada node master atau pada node slave. Gambar 5 merupakan contoh pengukuran response time dari perangkat master. pengukuran dimulai setelah master mengirimkan paket data sampai dengan saat slave memberikan data.

pada Gambar 5, master di konfigurasikan untuk mengirim paket data (PD) dengan jumlah dan periode waktu pengiriman (T) yang telah ditentukan. Setelah Master mengirim semua paket data, Slave akan mengirmkan semua paket data yang telah diterima, untuk dilakukan pencocokan antara data yang dikirim Master dan yang diterima Slave. Respon Time didapat dari $\mathrm{T}$ terkecil saat slave masih dapat menerima semua paket data dengan baik.

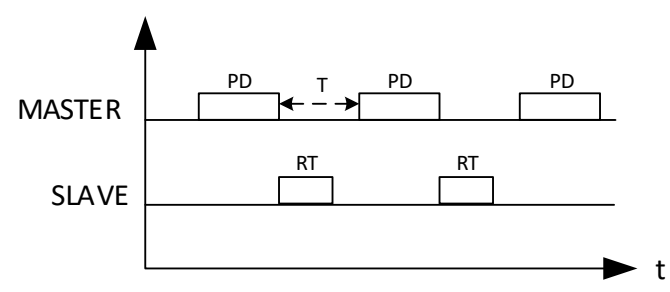

PD : Paket Data

RT : Respon Time

$\mathrm{T}$ : Periode Pengiriman PD

Gambar 5. Pengukuran Response Time

\section{Hasil dan Pembahasan}

Desain dan implementasi perangkat untuk komunikasi RS-485 pada embedded system ditunjukan pada Gambar 6 dan Gambar 7. Pada desain digunakan depelopment board Arduino pro mini dengan basis mikrokontroller ATmega328P. komunikasi serial menggunakan modul USART pada mikrokontroller. Data serial dalam level TTL kemudian dikonversi menjadi level RS-485 oleh chip MAX485. Chip ini merupakan chip standar ANSI/EIA/TIA-485-A. pada standar ini mengatur karakteristik spesifik pada layer fisik komunikasi. 


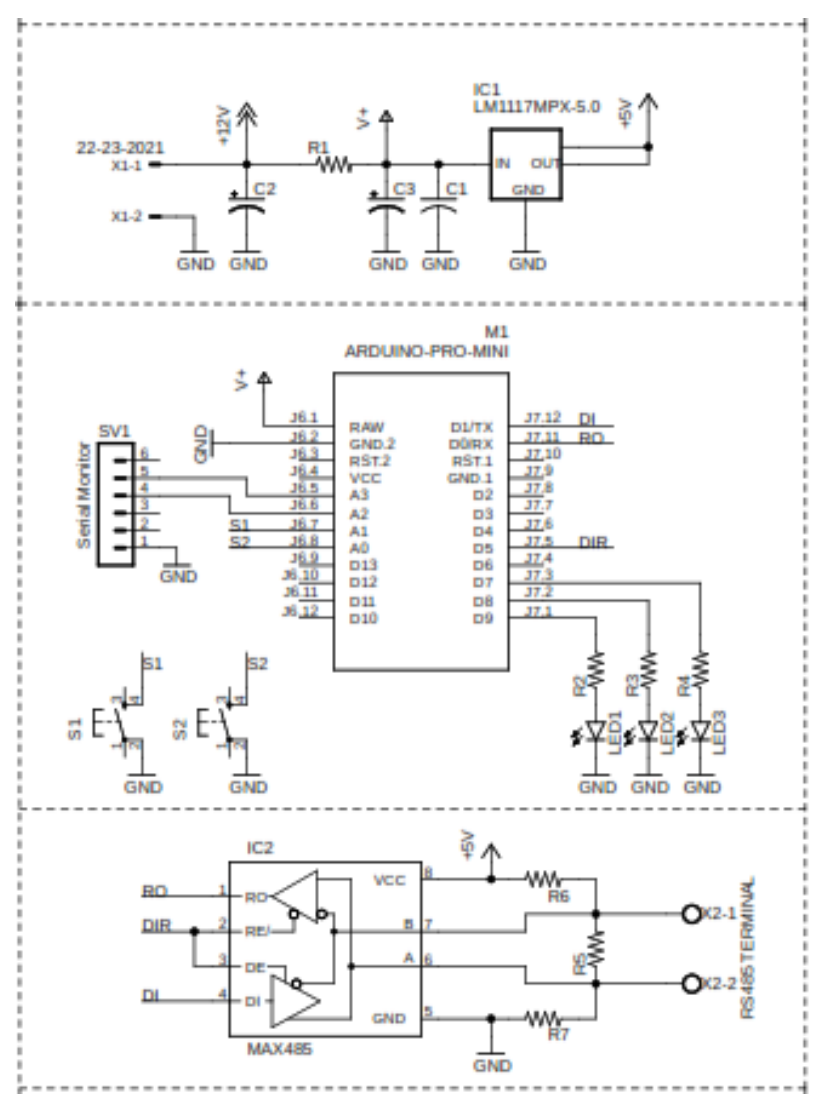

Gambar 6. Desain rangkaian Slave

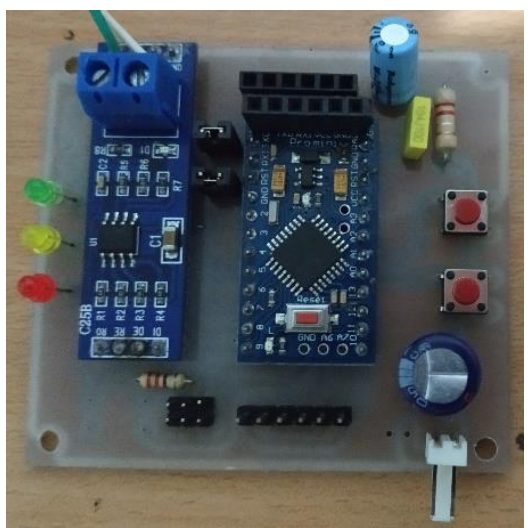

Gambar 7. tampilan Modul Slave

Pada penelitian ini dilakukan 3 jenis pengujian, yaitu pengujian dengan broadcast, addressing slave dan addressing dengan respon data. Pengujian tersebut menggunakan blok diagram rangkaian yang ditunjukan pada Gambar 8. Antara USB to RS-485 ke Slave 1, Slave 1 ke Slave 2 dan Slave 2 ke Slave 3 terhubung menggunakan kabel penghantar dengan panjang $2 \mathrm{~m}$, sedangkan kecepatan transmisi data yang digunakan sebesar 9600bps. Untuk tujuan pengujian setiap modul slave ditambahkan sebuah port komunikasi untuk tujuan mengirimkan paket data yang telah diterima pada jalus bus RS-485. Personal Computer (PC) digunakan sebagai perangkat master, dan juga sebagai perangkat monitor yang akan menerima data dari modul slave. Data yang dimonitor ini merupakan paket data yang diterima modul slave pada jalur komunikasi RS-485. Untuk itu pada PC digunakan 4 buah Port Komunikasi Serial, yang terdiri dari 1 port untuk mengirim/menerima data dari bus RS485, dan 3 buah port untuk menerima data dari masing modul slave. Pengiriman data monitor dilakukan pada saat slave dalam kondisi idle.

\section{A. Pengujian dengan broadcast}

Pengujian ini bertujuan untuk melihat kinerja perangkat slave dalam menerima paket data. Paket data dikirimkan dengan periode pengiriman antar paket data sebesar $10 \mathrm{~ms}, 8 \mathrm{~ms}, 6 \mathrm{~ms}, 4 \mathrm{~ms}, 2 \mathrm{~ms}$. Sebuah paket data pada pengujian ini memiliki panjang sebesar 11 Byte dengan format sesuai dengan Gambar 2(a) dimana 8 Byte digunakan sebagai parameter perintah.

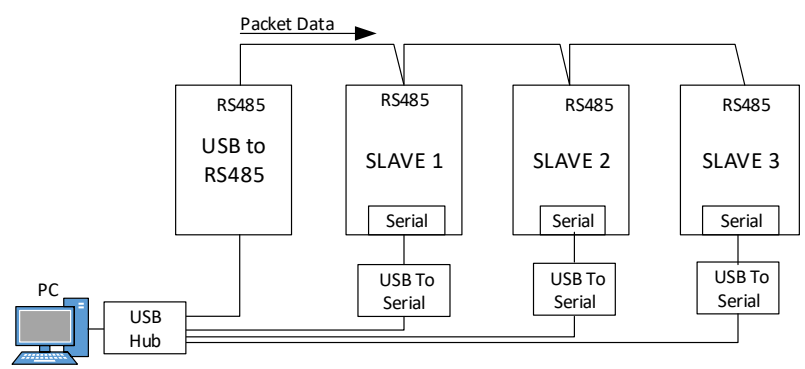

Gambar 8. Blok Diagram Rangkaian Pengujian Komunikasi RS-485

Gambar 9 menunjukan model pengiriman data yang digunakan. Pada pengujian ini dikirimkan sebanyak 50 paket data broadcast

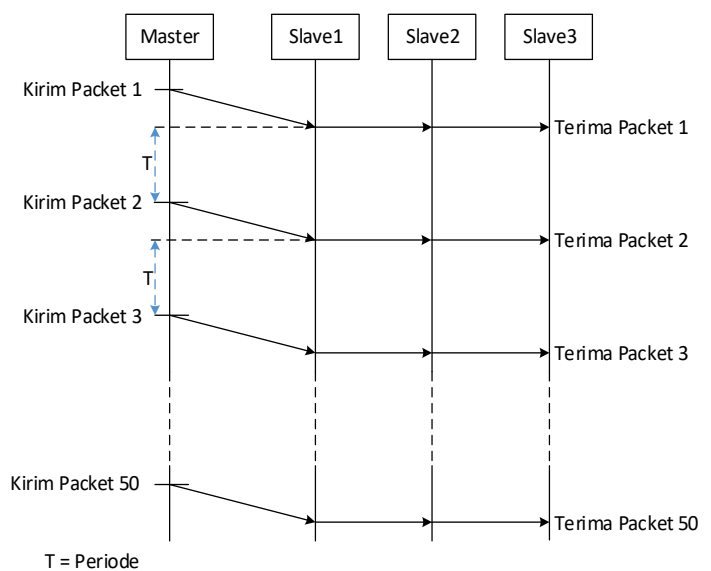

Gambar 9. Model pengiriman paket data pada pengujian broadcast

Pada pengujian ini akan hitung jumlah data yang hilang saat proses transmisi terhadap perubahan periode pengiriman. Pengiriman paket data ke jalur komunikasi RS-485 dilakukan dengan Applikasi yang dibuat menggunakan pemprogramman C pada PC, Gambar 10 Menunjukan Tampilan aplikasi tersebut. Hasil pengukuran ini ditunjukan pada table 1. Dari percobaan ini dapat dilihat bahwa slave dapat menerima paket data dari master dengan baik dengan interval waktu pengiriman paket lebih besar dari $8 \mathrm{~ms}$. Jika antar paket 
data yang dikirim lebih kecil dari nilai ini maka resiko kehilangan data saat pengiriman makin besar pula.

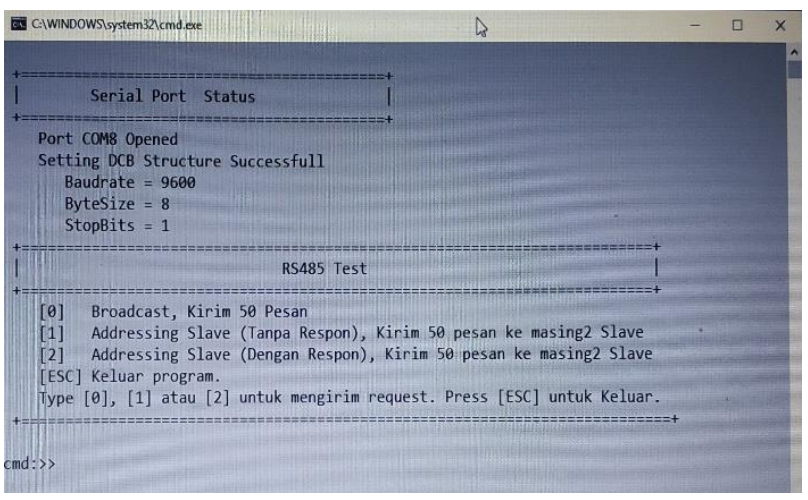

Gambar 10. Tampilan program Applikasi pada PC untuk mengirim data ke jalur komunikasi RS-485

Tabel 1. Hasil pengukuran jumlah data yang diterima modul slave saat pengiriman paket data secara Broadcast

\begin{tabular}{llll}
\hline \multirow{2}{*}{$\begin{array}{c}\text { Periode } \\
\text { Pengiriman }\end{array}$} & \multicolumn{3}{c}{ Jumlah paket data diterima } \\
\cline { 2 - 4 } & Salve 1 & \multicolumn{1}{c}{ Salve 2 } & \multicolumn{1}{c}{ Salve 3 } \\
\hline $10 \mathrm{~ms}$ & $100 \%$ & $100 \%$ & $100 \%$ \\
\hline $9 \mathrm{~ms}$ & $100 \%$ & $100 \%$ & $100 \%$ \\
\hline $8 \mathrm{~ms}$ & $100 \%$ & $100 \%$ & $100 \%$ \\
\hline $7 \mathrm{~ms}$ & $25.6 \%$ & $25.6 \%$ & $25.6 \%$ \\
\hline $6 \mathrm{~ms}$ & $0 \%$ & $0 \%$ & $0 \%$ \\
\hline $5 \mathrm{~ms}$ & $0 \%$ & $0.3 \%$ & $0.3 \%$ \\
\hline $4 \mathrm{~ms}$ & $0 \%$ & $0 \%$ & $0 \%$ \\
\hline
\end{tabular}

\section{B. Pengujian dengan slave addressing}

Spesifikasi data yang dikirimkan pada pengujian ini sedikit berbeda dengan pengujian sebelumnya. Perbedaan terletak pada 'SLV ADDR' yang berisi alamat slave tujuan, dan dengan panjang paket data sebesar 11 Byte. Model pengiriman data pada pengujian ini ditunjukan pada Gambar 11. Paket data dikirim secara squensial dimulai dari paket data untuk slave 1, slave 2 dan slave 3 . Periode pengiriman untuk squensial berikutnya dimulai kembali setelah jeda sebesar $10 \mathrm{~ms}, 9 \mathrm{~ms}, 8 \mathrm{~ms}, 7 \mathrm{~ms}, 6 \mathrm{~ms}$, $5 \mathrm{~ms}$ dan $4 \mathrm{~ms}$. Peroses pengiriman ini diulang $50 \mathrm{kali}$ untuk setiap slave.

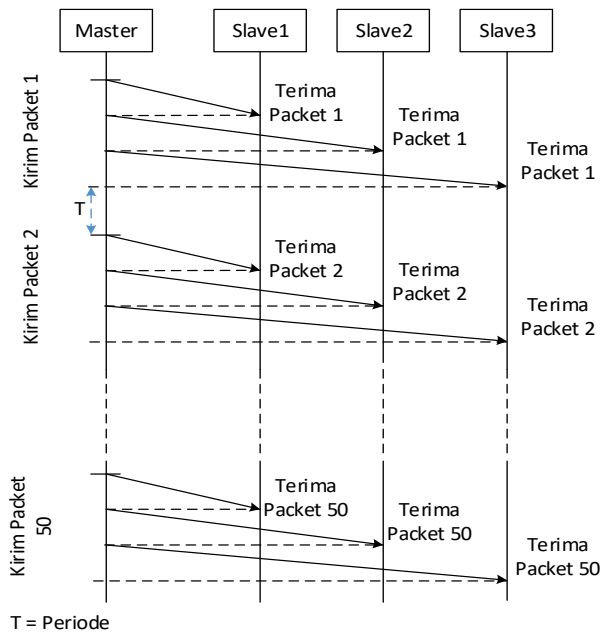

Gambar 11. Model pengiriman paket data pada pengujian slave addressing
Pada pengujian ini juga diukur jumlah data yang hilang selama proses transmisi. Hasil pengujian ditunjukan pada table 2. Dari table ini kehilangan data mulai terjadi saat periode pengiriman sebesar $8 \mathrm{~ms}$ dan semakin kecil periode pengiriman maka resiko kehilangan data akan semakin besar.

Tabel 2. Hasil pengukuran jumlah data yang diterima modul slave saat pengiriman paket data secara Slave Addressing

\begin{tabular}{llll}
\hline \multirow{2}{*}{$\begin{array}{c}\text { Periode } \\
\text { Pengiriman }\end{array}$} & \multicolumn{3}{c}{ Jumlah paket data diterima } \\
\cline { 2 - 4 } & \multicolumn{1}{c}{ Salve 1 } & \multicolumn{1}{c}{ Salve 2 } & Salve 3 \\
\hline $10 \mathrm{~ms}$ & $100 \%$ & $100 \%$ & $100 \%$ \\
\hline $9 \mathrm{~ms}$ & $100 \%$ & $100 \%$ & $100 \%$ \\
\hline $8 \mathrm{~ms}$ & $99.6 \%$ & $98.8 \%$ & $99.2 \%$ \\
\hline $7 \mathrm{~ms}$ & $98 \%$ & $98.8 \%$ & $99.2 \%$ \\
\hline $6 \mathrm{~ms}$ & $86.4 \%$ & $83.2 \%$ & $88.8 \%$ \\
\hline $5 \mathrm{~ms}$ & $7.2 \%$ & $8.8 \%$ & $9.2 \%$ \\
\hline $4 \mathrm{~ms}$ & $0 \%$ & $0 \%$ & $0 \%$ \\
\hline
\end{tabular}

\section{Pengujian dengan slave addressing dan respons}

Spesifikasi data yang dikirim pada pengujian ini tidak jauh berbeda dengan pengujian sebelumnya. Perbedaan hanya terdapat pada 'cmd' yang berisi perintah yang mengindikasikan master meminta response dari slave. Model pengujian ini ditunjukan pada Gambar 12.

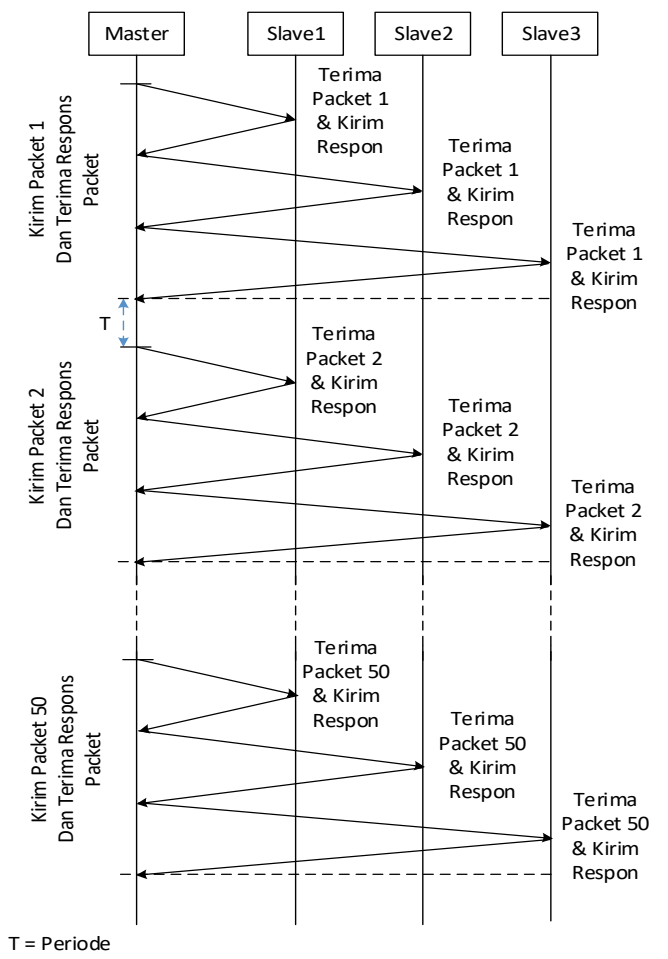

Gambar 12. Model pengiriman data pada pengujian slave addressing dengan response

Setiap master mengirim paket data ke slave, master akan menunggu data response dari slave tersebut. Setelah data diterima, master kembali mengirimkan paket data ke modul slave berikutnya. Table 3 menunjukan hasil pengujian dengan periode sebesar 10ms sampai dengan Oms. Dari table ini tampak bahwa pengujian addressing slave dengan response tidak berpengaruh terhadap perubahan periode pengiriman. hal ini mengindikasikan 
bahwa slave dapat dialamati kembali setelah sebelumnya mendapatkan perintah yang sama. Hal ini berbeda dengan saat slave mendapat perintah broadcast, dimana saat itu slave memerlukan waktu sebesar $8 \mathrm{~ms}$ sebelum mendapat perintah broadcast kembali.

Tabel 3. Hasil pengukuran jumlah data yang diterima modul slave saat pengiriman paket data secara Slave Addressing dengan Response

\begin{tabular}{lcccccc}
\hline \multirow{2}{*}{$\begin{array}{c}\text { Periode } \\
\text { Pengiriman }\end{array}$} & \multicolumn{2}{c}{\begin{tabular}{c} 
Jumlah paket data yang diterima (\%) \\
\cline { 2 - 7 } SL1
\end{tabular}} & $\begin{array}{c}\text { MS }<> \\
\text { SL2 }\end{array}$ & \multicolumn{1}{c}{ MS $<$ SL3 } \\
\hline $10 \mathrm{~ms}$ & 100 & 100 & 100 & 100 & 100 & 100 \\
\hline $9 \mathrm{~ms}$ & 100 & 100 & 100 & 100 & 100 & 100 \\
\hline $8 \mathrm{~ms}$ & 100 & 100 & 100 & 100 & 100 & 100 \\
\hline $7 \mathrm{~ms}$ & 100 & 100 & 100 & 100 & 100 & 100 \\
\hline $6 \mathrm{~ms}$ & 100 & 100 & 100 & 100 & 100 & 100 \\
\hline $5 \mathrm{~ms}$ & 100 & 100 & 100 & 100 & 100 & 100 \\
\hline $4 \mathrm{~ms}$ & 100 & 100 & 100 & 100 & 100 & 100 \\
\hline $3 \mathrm{~ms}$ & 100 & 100 & 100 & 100 & 100 & 100 \\
\hline $2 \mathrm{~ms}$ & 100 & 100 & 100 & 100 & 100 & 100 \\
\hline $1 \mathrm{~ms}$ & 100 & 100 & 100 & 100 & 100 & 100 \\
\hline 0 & 100 & 100 & 100 & 100 & 100 & 100 \\
\hline
\end{tabular}

\section{KESIMPULAN}

Berdasarkan hasil pengujian pada perangkat masterslave berbasis komunikasi RS-485, dapat disimpulkan bahwa protokol komunikasi yang ditanamkan pada embedded system berbasis mikrokontroller ATmega328, dan dengan kecepatan transmisi data pada jalur komunikasi RS-485 sebesar 9600bps memiliki response time sebesar $8 \mathrm{~ms}$ saat menerima paket data secara broadcast. Sedangkan saat paket data diterima secara addressed, response time menjadi sebesar $7 \mathrm{~ms}$. Untuk pengujian pengiriman paket data secara addressed dengan response, maka didapatkan bahwa periode pengiriman data tidak berpengaruh. Hal ini menunjukan bahwa setelah selesai mengerjakan perintah dari paket data ini maka modul slave dapat menerima paket data berikutnya.

\section{UCAPAN TERIMA KASIH}

Terima kasih disampaikan kepada P3M Politeknik Negeri Samarinda yang telah memberikan dukungan dan dana dalam penelitian ini.

\section{DAFTAR PUSTAKa}

[1] H. A. Alshazly and M. Hassaballah, "An Embedded System for a Bluetooth Controlled Mobile Robot Based on the ATmega8535 Microcontroller," Egypt. Comput. Sci. J., vol. 40, no. 1, pp. 61-72, 2016.

[2] A. Wajiansyah, H. Purwadi, A. Astagani, and S. Supriadi, "Implementation of master-slave method on multiprocessor-based embedded system: case study on mobile robot," Int. J. Eng. Technol., vol. 7, no. 2, pp. $53-$ $56,2018$.

[3] H. Marais, "Analog Device Application Note (AN-960), RS-485/RS-422 Circuit Implementation Guide," 2008.

[4] K. S. Wibawa, A. A. K. O. Sudana, and P. W. Buana, "Mikrokontroler Sistem Komunikasi Sensor Jamak Menggunakan Serial Rs-485 Multi Processor Communication," LONTAR Komput., vol. 7, no. 2, pp. 122-131, 2016.

[5] M. Siva, R. Krishna, K. Dinesh, and N. S. Shanbog, "Low Cost Remote Monitoring of Solar Plant through RS485 Communication," Int. J. Innov. Technol. Explor. Eng., vol. 8, no. 9, pp. 3034-3037, 2019.

[6] A. S. Ashtekar, B. J. Parvat, and C. B. Kadu, "Application of MODBUS to Communicate the PLC and Lab VIEW for Real Time Process Control," no. 11, pp. 41-45, 2013.

[7] A. W. Wardhana, "Monitoring and Control System for Building Application Using MODBUS Remote Terminal Unit Protocol With AVR Atmega Family Microcontroller," vol. 6, no. 2, pp. 1-11, 2016.

[8] L. Huang and J. Su, "A Context Aware Smart Classroom Architecture for Smart Campuses," Appl. Sci., vol. 9, no. 1837, pp. 1-34, 2019.

[9] Y. Xie, M. Yu, J. Fu, D. Chen, and C. Yang, “A hazmat transportation monitoring system based on Global Positioning System/Beidou Navigation Satellite System and RS485 bus," Proc. - 2016 9th Int. Congr. Image Signal Process. Biomed. Eng. Informatics, CISP-BMEI 2016, pp. 1059-1063, 2017.

[10] Y. Lu, T. Hu, and X. Wang, "Information centric networking media streaming experiment platform design," in Smart Computing and Communication, Second International Conference, SmartCom 2017, 2017, vol. 10699 LNCS, pp. 332-343. 